\title{
MAT2A Inhibitor AG-270
}

National Cancer Institute

\section{Source}

National Cancer Institute. MAT2A Inhibitor AG-270. NCI Thesaurus. Code C153180.

An orally available small molecule inhibitor of methionine adenosyltransferase II alpha (MAT2A) with potential antineoplastic activity. Upon administration, AG-270 inhibits the activity of MAT 2A, a metabolic enzyme responsible for the production of S-Adenosyl-Lmethionine (SAM), a primary donor of methyl groups in cellular transmethylation reactions that regulate gene expression, cell growth, and differentiation. MAT2A activity is selectively essential in cancer cells deficient in methylthioadenosine phosphorylase (MTAP), a critical enzyme in the methionine salvage pathway, that is deleted in some human cancers. Inhibition of MAT2A may potentially inhibit tumor cell growth in MTAPdeleted cancers that rely heavily on SAM synthesis. 